\title{
Capillary Limit of a Miniature Loop Heat Pipe with Multiple Evaporators and Multiple Condensers
}

\author{
Hosei Nagano* \\ Keio University, Yokohama, Kanagawa, 223-8522, Japan \\ and \\ Jentung $\mathrm{Ku}^{\dagger}$ \\ NASA Goddard Space Flight Center, Greenbelt, Maryland 20771
}

\begin{abstract}
An experimental investigation of a miniature loop heat pipe with multiple evaporators and multiple condensers were conducted in order to evaluate its capillary limit. The experimental tests were conducted by varying heat load to one or both evaporators, with and without active temperature control of compensation chamber (CC) using the thermoelectric devices, and variable tilts between the evaporators and the CCs. The physical process of the loop and thermal conductance of the heat leak from evaporator to (CC) were discussed based on the test results. The difference of the temperature profiles between with and without active control of $\mathrm{CC}$ temperature was evaluated. The effect of the gravity on capillary limit and $\mathrm{CC}$ temperature was also evaluated by comparing the test result in horizontal position with that in vertical position. The loop recovery after capillary limit was exceeded was also described.
\end{abstract}

\section{Nomenclature}

$G_{\text {COND }}=$ thermal conductance between the evaporator and the CC

$\dot{m} \quad=$ mass flow rate

$P_{C A P} \quad=$ capillary pressure

$Q_{L E A K} \quad=$ heat leak

$Q_{L} \quad=$ heat load to evaporator

$r_{P}=$ radius of curvature of the wick at the vapor/liquid interface

$T_{c C} \quad=\quad \mathrm{CC}$ temperature

$T_{E V A P}=$ vapor temperature in the evaporator grooves

$\Delta P_{\text {TOT }}=$ total pressure drop in LHP

$\Delta v \quad=$ difference in specific volume between the liquid and vapor phases

$\sigma \quad=$ surface tension force

$\lambda=$ latent heat of vaporization of the working fluid

$\theta \quad=$ contact angle between the liquid and solid

\section{Introduction}

T oop heat pipe (LHP) which utilize surface tension forces developed in fine porous wick to circulate fluid can transfer large heat loads over long distances with small temperature differences and no external pumping power. A basic LHP consists of an evaporator, a condenser, a compensation chamber (CC), and vapor and liquid lines. The evaporator is made with an integral $\mathrm{CC}$ with a bayonet and a secondary wick connecting these two elements. The

\footnotetext{
* NASA Visiting Researcher, Thermal Engineering Branch, Greenbelt Rd., Greenbelt, Maryland 20771 AIAA Member.

${ }^{\dagger}$ Group Leader, Thermal Engineering Branch, Technology Development Group, Greenbelt Rd., Greenbelt, Maryland 20771.
} 
CC saturation temperature determines the loop operating temperature. Because the $\mathrm{CC}$ is physically near the evaporator and is located in the path of the fluid circulation, its temperature is a function of the loop operating conditions such as the evaporator heat load, condenser sink temperature, and ambient temperature. Under the normal operation, the overall pressure drop in the loop must not exceed the capillary pumping capability of the wick. In addition, the thermodynamic constraint requires that the temperature difference between the evaporator and the CC match the corresponding pressure drop across the primary wick [1].

For multiple heat sources or a heat source with a large thermal footprint that needs to be cooled, an LHP with multiple evaporators will be very desirable. The feasibility of a multiple-evaporator LHP has been demonstrated [25]. There are several challenges for such a system. A simple thermodynamic analysis shows that, under most conditions, only one of the CCs will contain two-phase fluid and control the loop operating temperature. All other CCs will be completely liquid-filled [1,6]. This characteristic has been experimentally verified through extensive testing of an LHP with two evaporators and two condensers [6-8]. Test results also show that control of the loop operating temperature can switch from one $\mathrm{CC}$ to another as the operating condition changes. Other issues such as interactions between individual CCs, temperature stability, and loop's adaptability to rapid power and sink temperature cycle were also investigated.

Heat transport capability is one of the most important elements to define the performances of heat transport devices. However capillary limit of LHP is difficult to define. The loop can continue to function after the event of vapor penetration and reach a steady state at a higher temperature. As the heat load increases further, the loop will reach another steady state at an even higher temperature. This behavior makes the concept of "heat transport limit in an LHP" rather ambiguous. Especially, the capillary limit of LHPs with multiple evaporators is more complex and difficult to ascertain.

Recently, a miniature LHP (MLHP) with two evaporators and two condensers has been developed at NASA Goddard Space Flight Center and a comprehensive test program has been executed in order to characterize the MLHP thermal performances including start-up behaviors, capillary limit, power cycle and sink cycle and their gravity dependences. This paper focuses on the capillary limit of the MLHP with two evaporators and two condensers. The MLHP high power tests were conducted to evaluate the heat transport limit of the MLHP and the loop behavior after the capillary limit was exceeded. The tests were conducted under various operating conditions: a) heat load to one evaporator only; b) even heat loads to both evaporators; c) no temperature control of either CC; d) the temperature of one or both CCs was controlled using the thermoelectric devices, and e) variable tilts between the evaporators and the CCs. The physical processes that lead to evaporator deprime and the recovery from the deprime will be described in detail. Some issues related to the heat transport limit of an LHP will also be addressed.

\section{Theoretical Background}

Figure 1 depicts the flow schematic and the corresponding pressure drop diagram for a typical LHP with two parallel evaporators and two parallel condensers. The capillary pressure that each wick is able to sustain can be expressed as:

$\Delta P_{C A P, i}=\frac{2 \sigma_{i} \cos \theta_{i}}{r_{P, i}}(i=1,2)$

where $\sigma$ is the surface tension force of the working fluid, $\theta$ is the contact angle between the liquid and solid, $r_{P}$ is the radius of curvature of the wick at the vapor/liquid interface, and the index $\mathrm{i}$ refers to individual evaporators. As the heat load is applied to the evaporators, a fluid flow will be established and a pressure drop will be present in each component of the LHP. The mass flow rate through each evaporator can be calculated as:

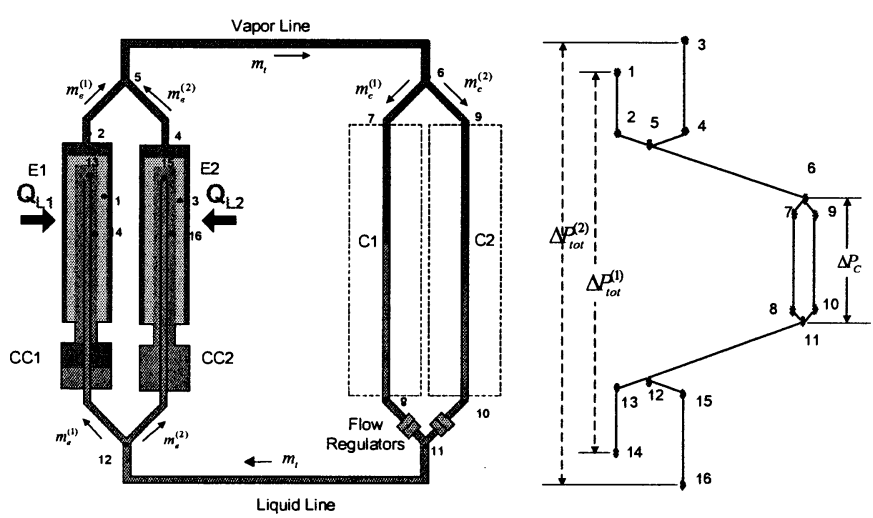

Fig. 1 Flow schematic and corresponding pressure drop diagram for an LHP with two evaporators and two condensers with heat load to both evaporators 


$$
\dot{m}_{i}=\frac{Q_{L, i}}{\lambda_{i}}(i=1,2)
$$

where $\dot{m}$ is the mass flow rate, $Q_{L}$ is the heat load and $\lambda$ the latent heat of vaporization of the working fluid. The total mass flow rate through the transport lines and the condenser is $\dot{m}_{T}=\dot{m}_{1}+\dot{m}_{2}$. In order for the LHP to function properly, each evaporator must be able to sustain the total pressure drop imposed upon its wick:

$$
\Delta P_{C A P, i} \geq \Delta P_{T O T, i} \quad(i=1,2)
$$

The equality sign holds true when the capillary limit is reached. The total pressure drop that the primary wick has to sustain is the sum of the pressure drops in the bayonet, primary wick, vapor grooves, vapor line, condenser, liquid line, and that due to the gravity head, i.e.

$$
\Delta P_{T O T, i}=\Delta P_{B A Y, i}+\Delta P_{W I C K, i}+\Delta P_{G R V, i}+\Delta P_{V A P, i}+\Delta P_{L I Q, i}+\Delta P_{C O N D}+\Delta P_{G, i}(i=1,2)
$$

In Fig. 1, it is assumed that evaporator 2 receives a higher heat load than evaporator 1. The pressure drop from point 5 to point 12 is common to both evaporators and is a function of the total heat load applied to the two evaporators. The pressure drops from point 1 to point 5 and from point 12 to point 14 are dependent upon the heat load to evaporator 1 only. Likewise, the pressure drops from point 3 to point 5 and from point 12 to point 16 are dependent upon the heat load to evaporator 2 only. Thus, the total pressure drop imposed upon each evaporator is a function of the total heat load as well as the heat load distribution between the two evaporators.

When the heat load is applied to only one of the evaporators, the evaporator receiving no heat load actually works as a condenser. Figure 2 shows the pressure drop diagram when evaporator 1 receives no external heat load. The flow from point 5 to point 12 (via point 2) is in a reverse direction. Consequently, the pressure drop that the evaporator 1 wick has to sustain could be much smaller than that shown in Figure 1. The exact amount of heat dissipation through evaporator 1 is determined by the conservation laws of mass, momentum, and energy among the two condensers and evaporator 1, and is a function of many factors, including the heat load, line sizes, condenser sink temperatures and ambient temperature. As the heat load to evaporator 2 increases, the pressure drops imposed upon both evaporators also increases. Whenever the pressure drop exceeds the capillary limit of either evaporator, the weaker evaporator will fail first.

Between the CC and evaporator outer grooves, which contain two-phase fluid, there is a relationship between the temperature difference and the pressure difference of these components, as expressed by the Clausius-Clapeyron equation:

$\Delta P_{T O T, i}-\Delta P_{W I C K, i}=\frac{\lambda\left(T_{E V A P, i}-T_{C C, i}\right)}{T_{C C, i} \cdot \Delta v_{i}}(i=1,2)$

$\Delta v_{i}$ is the difference in specific volume between the liquid and vapor phases, $T_{E V A P, i}$ is the vapor temperature in the evaporator grooves, and $T_{C C, i}$ is $\mathrm{CC}$ temperature. Thus, for a given pressure drop in the loop, a corresponding temperature difference exists between the evaporator and the CC. Such a temperature difference affects the heat leak from the evaporator to the $\mathrm{CC}$, which can be expressed as:

$$
Q_{L E A K, i}=G_{C O N D, i}\left(T_{E V A P, i}-T_{C C, i}\right)(i=1,2)
$$

where $G_{C O N D, i}$ is the thermal conductance between the evaporator and the CC. The heat leak is a critical component in determining the $\mathrm{CC}$ saturation temperature, which in turn governs the loop operating temperature. The thermal 
conductance, $G_{C O N D, i}$, is highly dependent upon the vapor void fraction in the evaporator core. If the evaporator core is completely filled with liquid, the heat leak is transmitted by heat conduction through the evaporator shell, and the thermal conductance is usually very small. If vapor exists in the evaporator core, the evaporator core becomes part of the CC. The heat can be transferred from the evaporator to the $\mathrm{CC}$ by conduction through the primary wick. The thermal conductance becomes large due to the short heat transfer path. Moreover, the higher the vapor void fraction, the larger the heat leak [1,9]. Since the pore sizes are not uniform, $r_{P}$ in Equation (1) refers to the largest (and hence the weakest) pore of the wick. As the weaker pores fail, vapor will penetrate through the wick and reach the evaporator core. Because the evaporator core can tolerate vapor presence, the stronger wick pores can continue to pump liquid and the loop can continue to work. However, vapor penetration results in a higher heat leak to the CC, and hence a higher operating temperature. Two things happen after vapor penetrates the wick. Because the surface tension decreases with an increasing temperature, more and more pores will fail, leading to more vapor penetration and an ever-increasing operating temperature. On the other hand, the viscosities of the fluid decrease with an increasing temperature, leading to a smaller total pressure drop. Consequently, a new steady state could be reached at a higher operating temperature if the capillary limit (the heat load) is not exceeded by too much. One indication that the capillary limit is exceeded is a rapid increase of the temperature difference between the evaporator and the $\mathrm{CC}$ due to a decreasing thermal conductance. Another indication is that the temperature of the CC connected to the failing evaporator will rise rapidly and begin to control the loop operating temperature regardless of which CC has been in control prior to the vapor penetration.

The heat transport capability of a capillary two-phase thermal system is measured by the maximum heat load it can carry without exceeding the allowable temperature. For some two-phase systems such as capillary pump loops, the maximum heat load is reached when the total pressure drop is equal to the capillary limit because any further increase in the heat load will lead to blockage of the liquid flow and hence a temperature excursion of the evaporator. This is not true for LHPs. The LHP can reach a new steady state even after the capillary limit is exceeded as described previously. Thus, the concept of a heat transport limit becomes more ambiguous. Both the capillary limit and the pressure drop are functions of the temperature, and there are many factors that can affect the LHP temperature. When multiple parallel evaporators are present, the transport limit is also a function of the heat load distribution among the evaporators, and thus there is a small range of values for the maximum heat load. The effect of various parameters on the capillary limit of an LHP with two evaporators is the subject of this investigation.

\section{Test Article and Test Set-up}

Figure 3 shows the schematic of the MLHP test article, which consists of two parallel evaporators, two parallel condensers, a common vapor transport line and a common liquid return line. Each evaporator has its own integral CC. Main features of this MLHP include 1) 6.35-mm O.D. evaporators. 2) Titanium primary wicks with 1.65 um pore size. 3) SS vapor and liquid transport lines with $2.38 \mathrm{~mm}$ and $1.59 \mathrm{~mm}$ O.D., respectively. 4) Aluminum condensers with $2.38 \mathrm{~mm}$ O.D.. 5) A thermoelectric cooler (TEC) is attached to each CC. A flow regulator made of capillary wick with 10.1 micron diameter is installed at the downstream of each condenser. The flow regulator prevents vapor from penetrating the wick before both condensers are fully utilized, and hence serve to balance the flows between the two condenses. The loop is charged with 29 grams of anhydrous ammonia. Table 1 shows the geometric parameters of the main components.

A 400-gram aluminum mass was attached to each evaporator to simulate the instrument mass. A cartridge heater was attached to each thermal mass to provide heat loads between $1 \mathrm{~W}$ and $150 \mathrm{~W}$ per evaporator. A TEC was attached to each CC. Copper thermal straps connect the rear side of the TEC to the evaporators. Each condenser was attached to a cold plate; and each cooled was cooled by a separate chiller. Figure 4 shows the schematic of the test loop with thermocouple locations. Seventy-two (72) thermocouples are used to monitor the loop temperatures. A data acquisition system consisting of a data logger, a personal computer, a CRT monitor, and Labview software is used to monitor and store data. The data is updated on the monitor and stored in the computer every second.

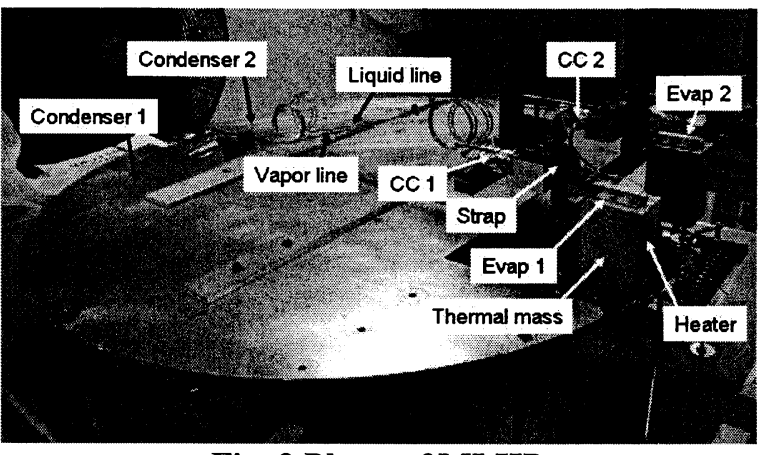

Fig. 3 Photo of MLHP 
Table 1. Summary of Design Parameters

\begin{tabular}{|l|l|}
\hline Evaporator & Aluminum 6061 \\
& $9.65 \mathrm{~mm}$ O.D. $52 \mathrm{~mm} \mathrm{~L}$ \\
\hline & Titanium \\
& $6.35 \mathrm{~mm}$ O.D. $\times 3.18 \mathrm{~mm} \mathrm{I.D}$ \\
Primary Wick & $1.65 \mathrm{um}$ pore size \\
\hline & $0.2 \mathrm{E}-13 \mathrm{~m}^{2}$ Permeability \\
\hline CC & SS 304 \\
\hline Vapor Line & $22.2 \mathrm{~mm}$ O.D. $\times 72.4 \mathrm{~mm} \mathrm{~L}$ \\
\hline Liquid Line & $2.38 \mathrm{~mm}$ O.D. \\
\hline Condenser & $1.59 \mathrm{~mm}$ O.D. \\
\hline Working fluid & $2.38 \mathrm{~mm}$ O.D. $\times 2540 \mathrm{~mm} \mathrm{~L}$ \\
\hline
\end{tabular}

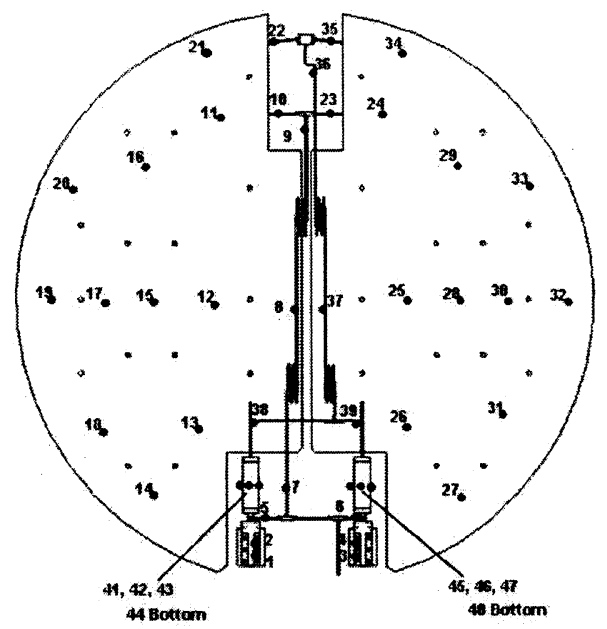

\section{Test Results}

More than 80 capillary limit tests were conducted in the atmospheric condition. In some tests, the $\mathrm{CC}$ temperatures were not controlled, i.e. each $\mathrm{CC}$ was allowed to reach its natural equilibrium temperature under the given test condition. In other tests, one or both of the CCs were kept at $303 \mathrm{~K}$ to $313 \mathrm{~K}$ by using TECs. Sink temperature of the condenser 1 and condenser 2 was varied from $253 \mathrm{~K} / 253 \mathrm{~K}$ to $283 \mathrm{~K} / 293 \mathrm{~K}$. Power profiles included heat load to one evaporator only and even heat loads to both evaporators. In several test, in order to evaluate the effects of the gravity under $1 \mathrm{G}$ condition, test were conducted in four different orientations: horizontal, vertical, sideway, and upsidedown. In most tests, the system heat load was raised to a higher level after the capillary limit had been exceeded so as to demonstrate that the loop could reach another steady state at a higher temperature.

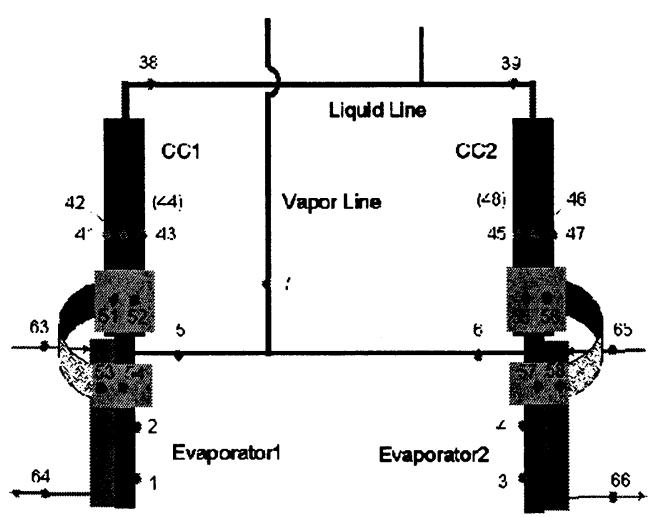

Figure 4. Thermocouple Location of MLHP Recovery of the evaporator was verified by reducing the heat load to the evaporators near the end of each test. In this paper, several typical test results will be presented, as listed in Table 2. Included in the table for each test are the power profile, condenser sink temperatures, and whether or not the CC temperatures were actively controlled.

In an LHP with multiple evaporators, only one of the CCs will contain two-phase fluid and control the loop operating temperature; all other CCs will be filled with liquid [6-8]. Moreover, control of the loop operating temperature may shift from one $\mathrm{CC}$ to another as the operating condition changes. In this test program, there were four thermocouples attached to each CC. It was observed throughout the test program that the CC containing twophase fluid displayed a uniform temperature while the liquid-filled CC displayed nonuniform, subcooled temperatures.

Table 2. Summary of the capillary limit tests

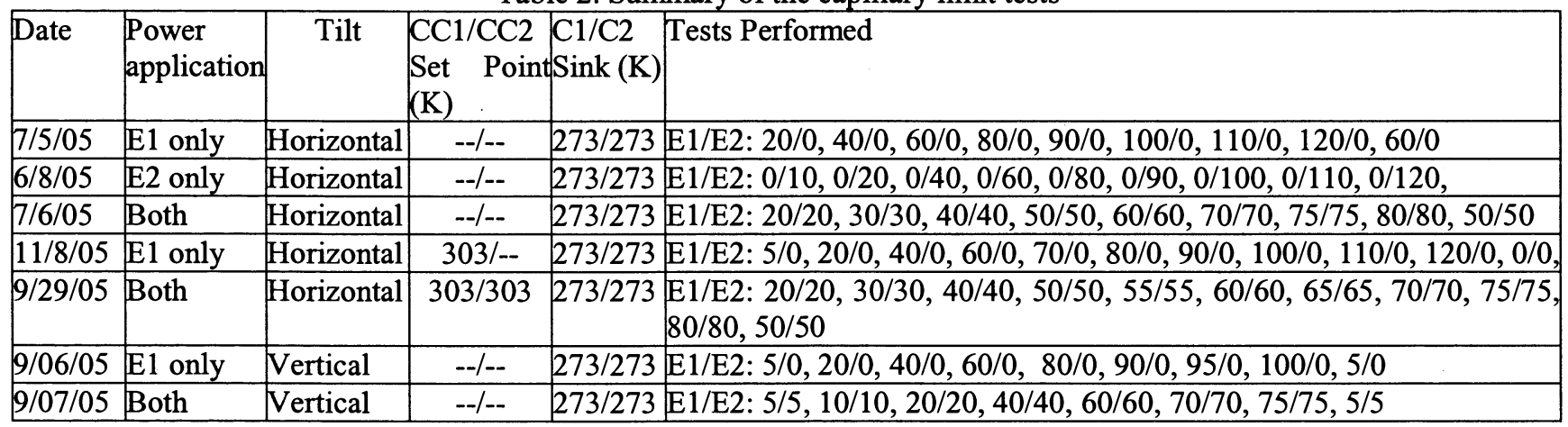


A. No active control of $\mathrm{CC}$ temperatures

1. Heat load to only E1

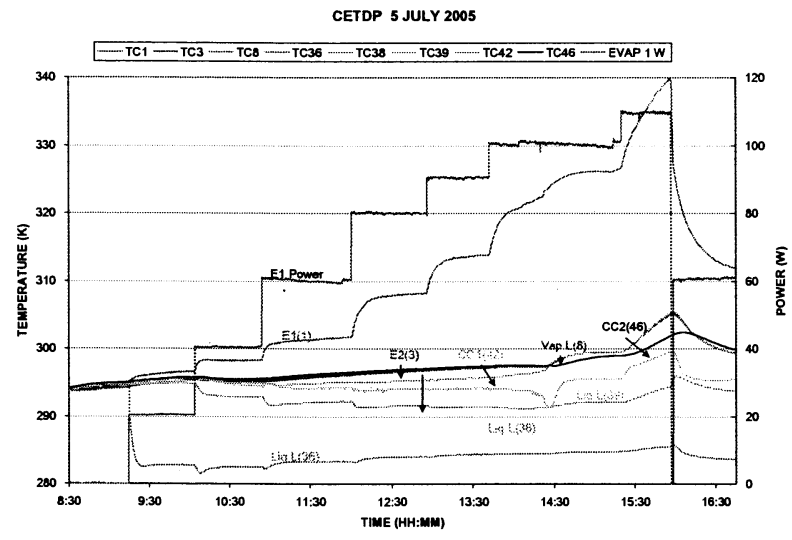

Fig. 5 Loop temperatures with heat load to E1 only

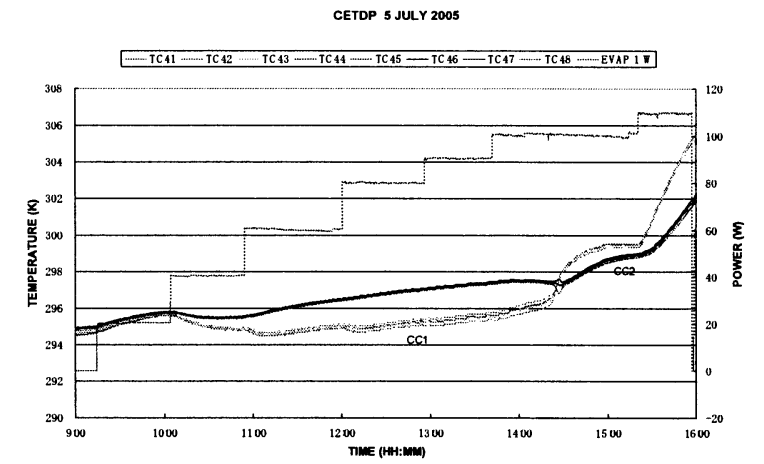

Fig. 6 CC temperatures with heat load to E1 only

Figure 5 illustrates the loop temperatures in a capillary limit test where the heat load was applied to E1 only. The $\mathrm{C} 1$ and $\mathrm{C} 2$ sink temperatures were kept at $273 \mathrm{~K} / 273 \mathrm{~K}$. Since E2 received no heat load, E2/CC2 worked as a condenser. Under such a condition, $\mathrm{CC} 2$ would always control the loop operating temperature prior to the loop reaching its capillary limit $[6,10]$. This was experimentally verified in this test for E1/E2 heat loads between $20 \mathrm{~W} / 0 \mathrm{~W}$ to $80 \mathrm{~W} / 0 \mathrm{~W}$. As shown in Fig. 6, in this power range the CC2 temperatures TC45 to TC48 were uniform and were higher than the $\mathrm{CC} 1$ temperatures TC41 to TC44 which were subcooled and spread. The capillary limit of E1 was exceeded at 100W/0W as evidenced by four accompanying events [10]. First, CC1 temperatures TC41 to TC44 became uniform and exceeded the CC2 temperatures TC45 to TC48, which became subcooled and spread. This suggested that vapor had penetrated through the E1 wick and $\mathrm{CC} 1$ began to control the loop operating temperature. Second, immediately following the vapor penetration, cold liquid was pushed from TC38 to TC39 along the liquid line, causing E2 inlet temperature TC39 to drop temporarily. Third, the CC1 temperature increased rapidly for a modest power increase. Fourth, the temperature difference between $\mathrm{E} 1$ and $\mathrm{CC} 1$ also increased rapidly for a modest power increase due to a decreasing thermal conductance after the vapor penetration. Nevertheless, the loop continued to function at a higher temperature. The loop also approached another steady temperature as the heat load further increased to $110 \mathrm{~W} / 0 \mathrm{~W}$. The loop completely recovered as the heat load was reduced to $60 \mathrm{~W} / 0 \mathrm{~W}$. However, the $\mathrm{CC} 1$ temperature was about $10 \mathrm{~K}$ higher than that at $60 \mathrm{~W} / 0 \mathrm{~W}$ prior to the vapor penetration, suggesting a residual effect from an earlier vapor penetration.

\section{Heat load to only E2}

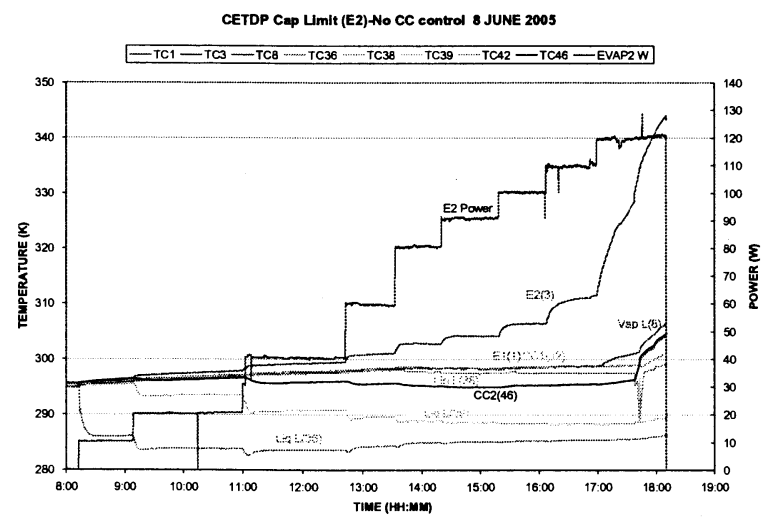

Fig. 7 Loop temperatures with heat load to E2 only

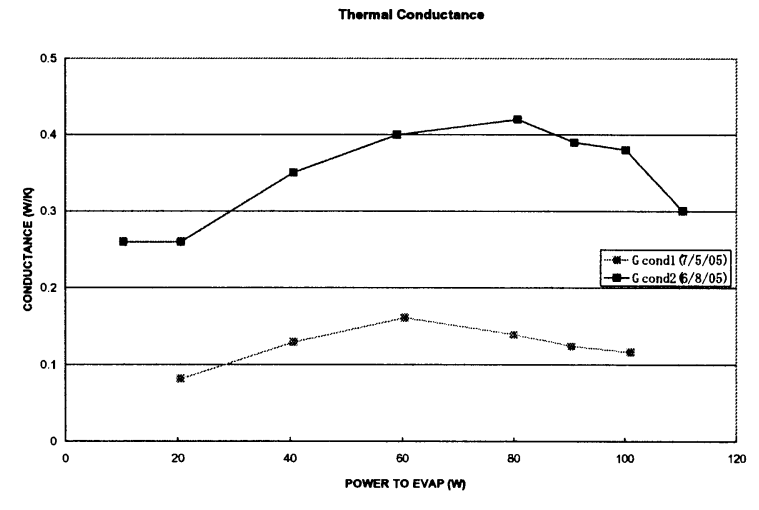

Fig. 8 Thermal conductance with heat load to one evaporator only 
Figure 7 shows the loop temperatures in a capillary limit test where the heat load was applied to E2 only. The C1 and $\mathrm{C} 2$ sink temperatures were kept at $273 \mathrm{~K} / 273 \mathrm{~K}$. This was the identical test to the previous test except the E2 power application. The different phenomena from the test where the heat load was applied to E1 only (7/5/05), were confirmed. Between $0 \mathrm{~W} / 10 \mathrm{~W}$ to $0 \mathrm{~W} / 110 \mathrm{~W}, \mathrm{E} 1 / \mathrm{CC} 1$ worked as a condenser, and CC1controlled loop operating temperature at about $300 \mathrm{~K}$, and $\mathrm{CC} 2$ was liquid-filled. When the power of $0 \mathrm{~W} / 120 \mathrm{~W}$ was applied, E2 temperature rose rapidly. Vapor line temperature of TC8 also began to rise, but neither of CC followed that temperature increase. At 17:30, which was 30 minutes after $120 \mathrm{~W} / 0 \mathrm{~W}$ power apply, CC2 temperature began to rise rapidly, and E2 temperature rose much higher rate. At this point, vapor penetration was occurred, and cold liquid was pushed from TC39 to TC38 along the liquid line, causing E1 inlet temperature TC38 to drop temporarily. Finally, E2 temperature reached acceptance temperature limit of this test system. Figure 8 illustrates thermal conductance of the E1 and CC1 in 7/5/05 test in Figure5 and of the E2 and CC2 in 6/8/05 test in Fig. 7. Thermal conductance was calculated from Eq. (6). $Q_{L E A K, i}$ is corresponded to heat exchange between the $\mathrm{CC}$ and the returned liquid, which is calculated from the mass flow rate in Eq. (2), specific heat capacity of the fluid, and the temperature difference between the saturation temperature and the inlet temperature, on condition that the heat exchange between $\mathrm{CC}$ and the environment is neglected. It was confirmed that the conductance of the $\mathrm{E} 1 / \mathrm{CC} 1$ has a peak at around $60 \mathrm{~W}$, while that of the $\mathrm{E} 2 / \mathrm{CC} 2$ has at around $80 \mathrm{~W}$. It was also confirmed that the thermal conductance of the $\mathrm{E} 2 / \mathrm{CC} 2$ was more than twice larger than that of the E1/CC1 although the evaporators and CCs of this MLHP was symmetrically designed. It is considered that although the $\mathrm{E} 1 / \mathrm{CC} 1$ and $\mathrm{E} 2 / \mathrm{CC} 2$ are macroscopically symmetric configuration, there are some differences in pore size of the wick or clearance of the evaporator components.

\section{Even heat load to both evaporators}

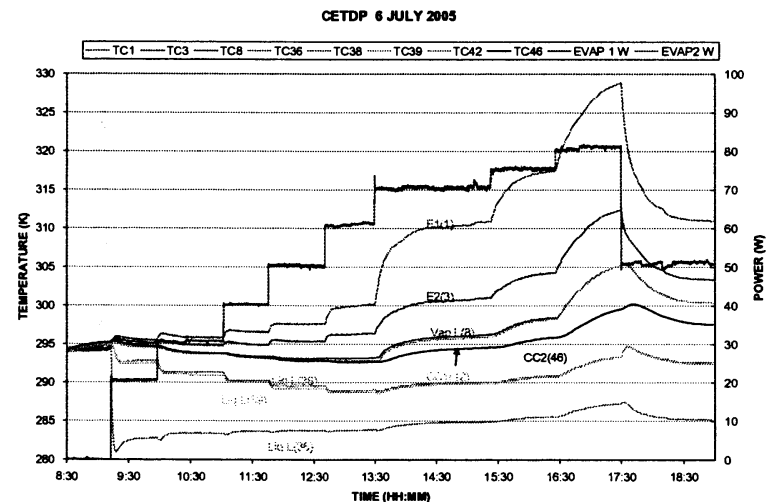

Fig. 9 Loop temperatures with heat load to both evaporators

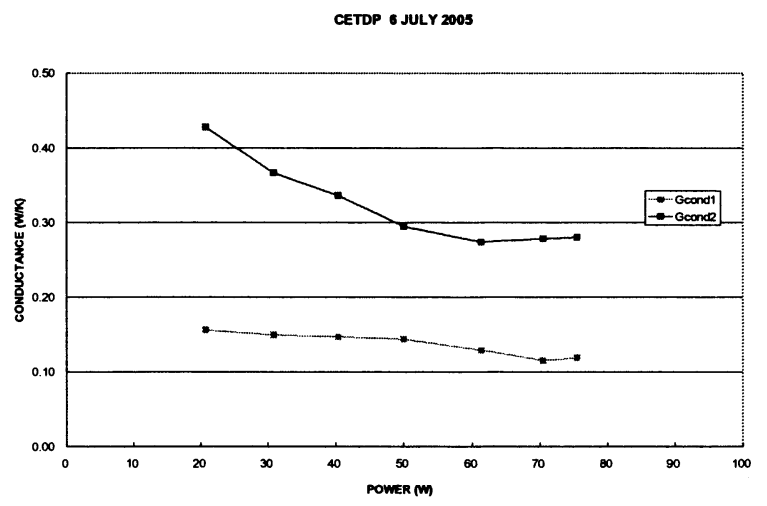

Fig. 10 Thermal conductance with heat load to both evaporators

Figure 9 shows the loop temperatures in a capillary limit test where the even heat load was applied to both evaporators. The $\mathrm{C} 1$ and $\mathrm{C} 2$ sink temperatures were kept at $273 \mathrm{~K} / 273 \mathrm{~K}$. Throughout the test, E1 temperature was always higher than E2 temperature though the evaporators of this MLHP were symmetrically designed. The evaporator temperatures began to rise rapidly at $70 \mathrm{~W} / 70 \mathrm{~W}$ for a modest power increase. CC1 temperature also rose and began to control the loop operating temperature. Even after capillary limit, however, the loop could operate steadily at a higher saturation temperature with $75 \mathrm{~W} / 75 \mathrm{~W}$ and $80 \mathrm{~W} / 80 \mathrm{~W}$. When the heat load was reduced to $50 \mathrm{~W} / 50 \mathrm{~W}$, the loop recovered from a dry-out. However, the CC1 and CC2 temperatures were $12 \mathrm{~K}$ and $9 \mathrm{~K}$ higher than that at $50 \mathrm{~W} / 50 \mathrm{~W}$ prior to the vapor penetration, suggesting a residual effect from an earlier vapor penetration. Figure 10 shows the conductance of each evaporator. The value of the conductance of the E2 was more than twice of E1. The remarkable peak of the conductance values was not confirmed.

\section{B. Active control of $\mathrm{CC}$ temperatures}

The CC temperature can be controlled at a fixed set point that is higher than its natural equilibrium temperature for a given test condition by using TEC control. When on of the CCs is controlled at the desired temperature, the 
other $\mathrm{CC}$ will be liquid-filled. With the loop operating at a constant temperature, the surface tension force and the capillary limit of each evaporator as expressed in Equation (1) are fixed.

\section{Heat load to only E1}

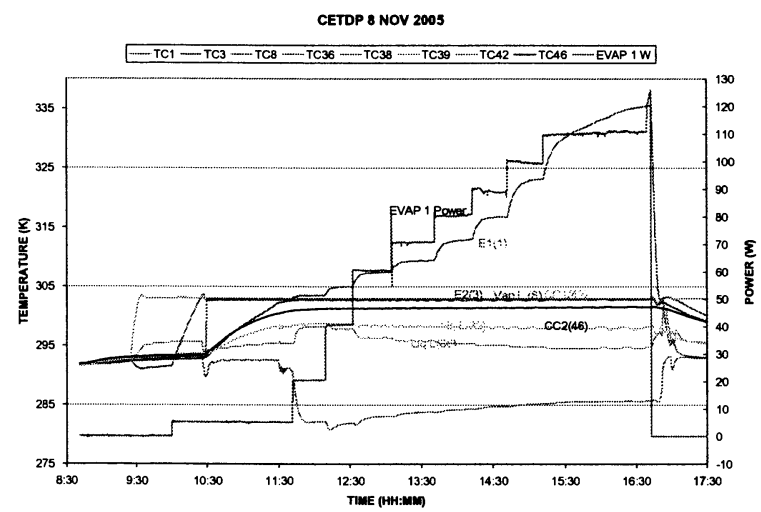

Fig. 11 Loop temperatures with heat load to E1 only with $\mathrm{CC}$ active control

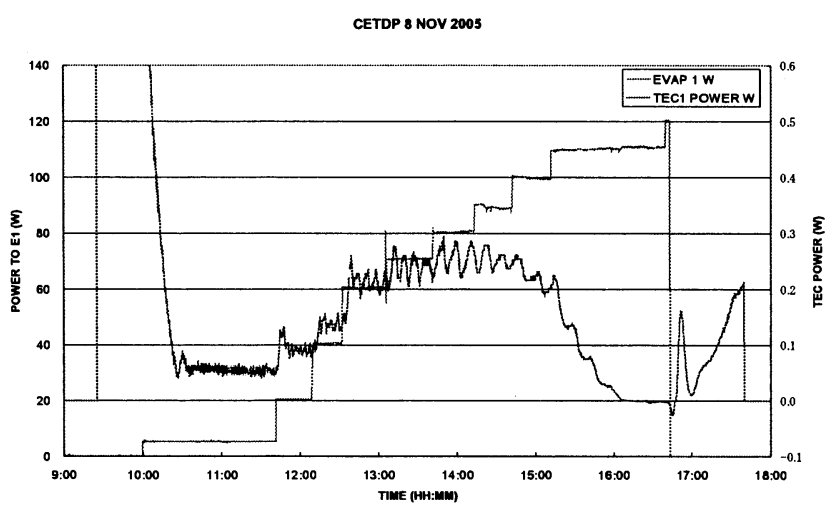

Fig. 12 TEC power with heat load to E1 only

Figure 11 shows the loop temperatures in a test where the $\mathrm{CC} 1$ temperature was controlled at $303 \mathrm{~K}$ and the heat load was applied to E1 only. The CC1 temperature could be maintained at $303 \mathrm{~K}$ for heat loads between $5 \mathrm{~W} / 0 \mathrm{~W}$ and $110 \mathrm{~W} / 0 \mathrm{~W}$. As E1 reached its capillary limit at $110 \mathrm{~W} / 0 \mathrm{~W}$, vapor penetrated through the E1 wick and the E1 temperature rose. However, $\mathrm{CC} 1$ temperature did not rise since $\mathrm{CC} 1$ was set at higher temperature than its natural equilibrium temperature below $110 \mathrm{~W}$. From the result of 7/5/05 test without CC temperature control shown in Figure 5, CC1 temperature began to increase and exceed $303 \mathrm{~K}$ at $110 \mathrm{~W}$. However, by using TEC control in this test, $\mathrm{CC} 1$ could be cooled and $\mathrm{CC} 1$ temperature was kept at 303K. In the test with $\mathrm{CC}$ temperature control by using TEC, it was more difficult to verify the capillary limit than the test without $\mathrm{CC}$ temperature control. Figure 12 shows the TEC power profile. At $110 \mathrm{~W} / 0 \mathrm{~W}$, it was confirmed that the power for heating began to decrease and finally, reached the negative power, which indicated in this test that the TEC control was switched from heating to cooling. When the power rose up to $120 \mathrm{~W} / 0 \mathrm{~W}$, the E1 kept rising and the temperature reached an upper limit of the test system and the power was autonomously turned off.

\section{Even heat load to both evaporators}

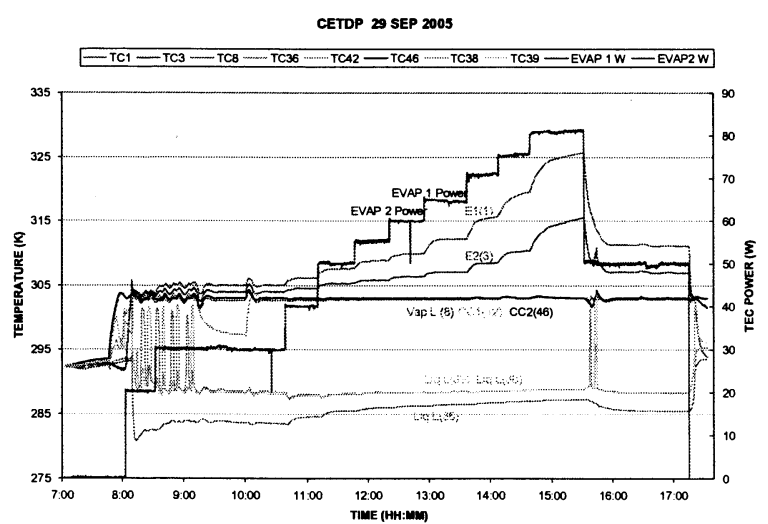

Fig. 13 Loop temperatures with heat load to both evaporators with $\mathrm{CC}$ active control

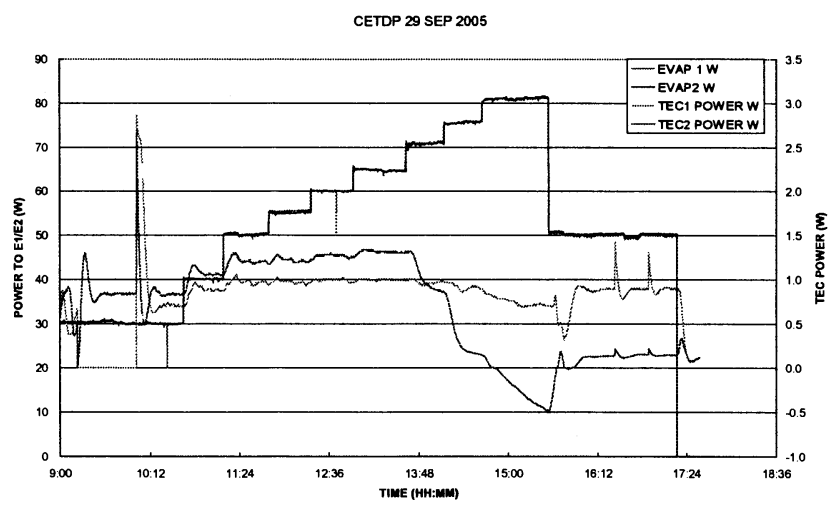

Fig. 14 TEC powers with heat load to both evaporators 
Figure 13 shows the loop temperature in the test where $\mathrm{CC} 1 / \mathrm{CC} 2$ were controlled at $303 \mathrm{~K}$ and even heat loads were applied to both $\mathrm{E} 1$ and $\mathrm{E} 2$. Throughout the test $\mathrm{CC} 1 / \mathrm{CC} 2$ were able to control the loop operating temperature at 303K. It was also more difficult to ascertain the capillary limit than the test without CC temperature control in Figure 7. Figure 14 illustrates the TEC power throughout the test. It was confirmed that at $70 \mathrm{~W} / 70 \mathrm{~W}, \mathrm{TEC} 1$ and TEC2 powers began to decrease, and at $80 \mathrm{~W} / 80 \mathrm{~W}$, TEC2 control was switched from heating to cooling. The loop completely recovered as the heat load was reduced to $50 \mathrm{~W} / 50 \mathrm{~W}$. However, the E1 and E2 temperature were $3 \mathrm{~K}$ and $2 \mathrm{~K}$ higher, and TEC powers were smaller than that at $50 \mathrm{~W} / 50 \mathrm{~W}$ prior to the vapor penetration.

\section{Gravity effects}

In order to evaluate the gravity effects, MLHP was set in vertical position, so that the evaporators are above CCs. The heat leak from the evaporator to the compensation chamber has profound effects on the loop operating temperature [1]. Such a heat leak depends on whether or not vapor exists inside the evaporator core, which in turn is a strong function of the elevation and tilt in one-G environments. The LHP operating temperature increases with increasing adverse elevations at low powers in ground operation. The increase of the operating temperature with the elevation can be explained as follows. As the pressure difference across the evaporator wick increases due to gravity head, the difference in saturation temperatures must also increase, as dictated by equation (5). Since the liquid enthalpy entering the compensation chamber does not change, the only way to satisfy the increasing pressure drop is by an increase in the evaporator vapor temperature. However, as the vapor temperature increases, the heat leak from the evaporator to the compensation chamber also increases. The compensation chamber temperature must then increase in order to provide enough liquid subcooling to compensate for the increased heat leak. A higher compensation chamber temperature requires an even higher evaporator vapor temperature. Such reciprocal effects accumulate quickly. In general, the effect of increasing pressure drop due to increasing heat load can be compensated for by an increasing liquid subcooling, $\dot{m} C_{P} \Delta T$, through the increase of the mass flow rate.

\section{Heat load to only El}

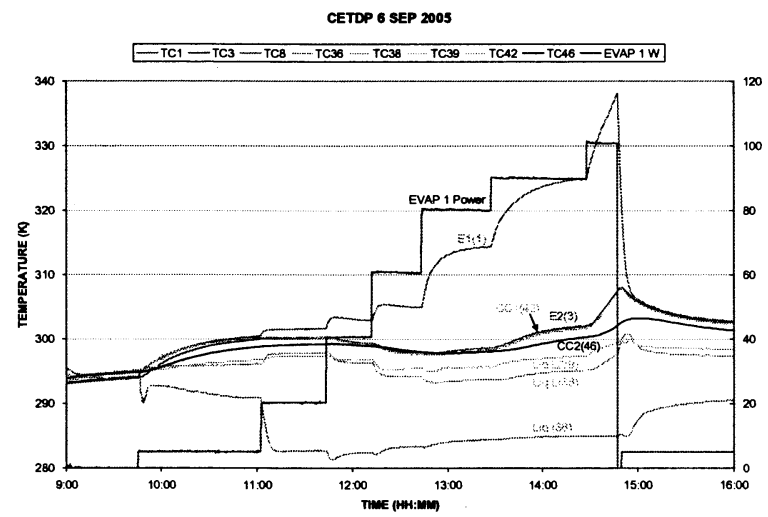

Fig. 15 Loop temperatures with heat load to E1 only with 90 deg tilt

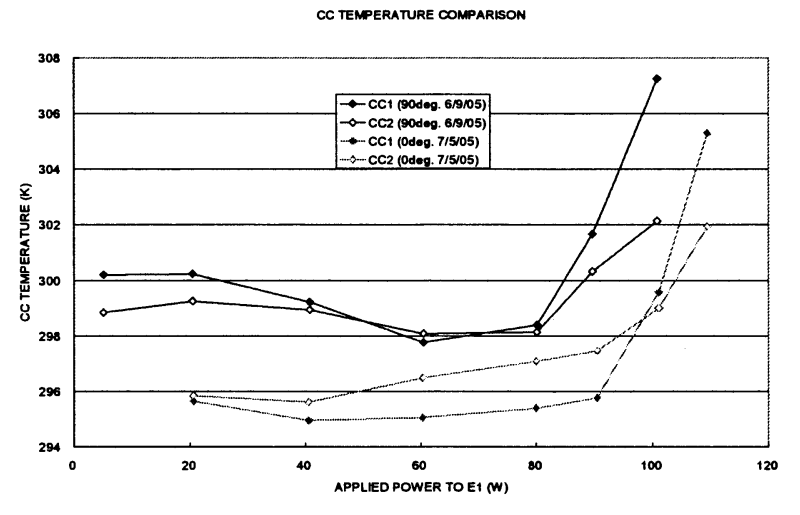

Fig. 16 Tilt angle dependence of $\mathrm{CC}$ temperatures with heat load to E1

Figure 15 shows the loop temperatures in a capillary limit test where the LHP was changed its configuration at $90 \mathrm{deg}$ and heat load was applied to E1 only. It was identical test with the 7/5/05 test in Figure 5 except the MLHP orientation. From $5 \mathrm{~W} / 0 \mathrm{~W}$ to $40 \mathrm{~W} / 0 \mathrm{~W}, \mathrm{CC} 1$ was controlled the loop operating temperature. At $60 \mathrm{~W} / 0 \mathrm{~W}$ power apply, CC2 began to control the loop. From $80 \mathrm{~W} / 0 \mathrm{~W}$, the $\mathrm{CC} 1$ controlled the loop again and E1 temperature rose rapidly. At this point the loop reached the capillary limit. After capillary limit, the loop could operate steadily at a higher saturation temperature with $90 \mathrm{~W} / 90 \mathrm{~W}$. At $100 \mathrm{~W} / 0 \mathrm{~W}, \mathrm{E} 1$ temperature sudden rose and the reached system upper limit. When the heat load was reduced to $5 \mathrm{~W} / 5 \mathrm{~W}$, the loop recovered from a dry-out. However, the CC1 and $\mathrm{CC} 2$ temperatures were a few $\mathrm{K}$ higher than that at $5 \mathrm{~W} / 5 \mathrm{~W}$ prior to the vapor penetration. Figure 16 shows the CC temperatures as a function of the applied power, comparing with the result in horizontal position conducted on $7 / 5 / 05$. Compared to the $7 / 5$ test, evaporator temperature was higher and the capillary limit was about $20 \mathrm{~W}$ lower. 


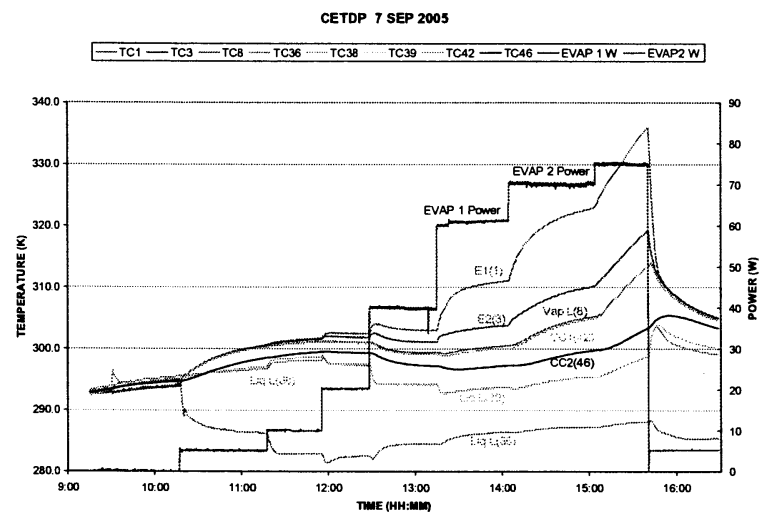

Fig. 17 Loop temperatures with heat load to both evaporators with 90 deg tilt

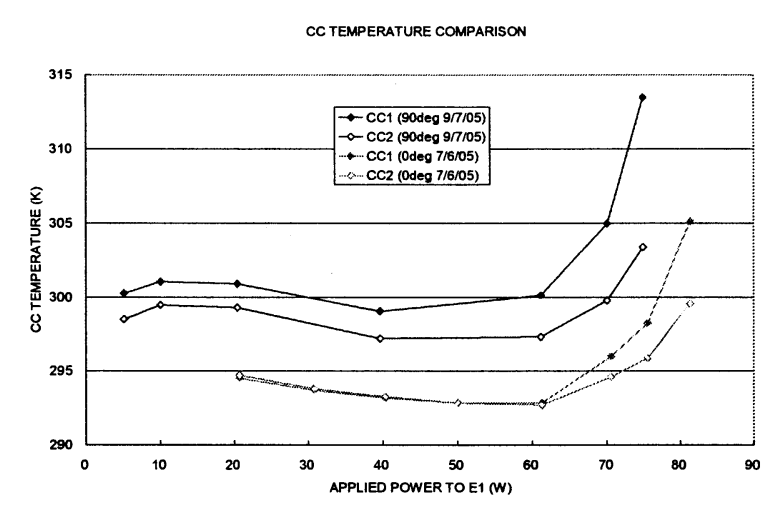

Fig. 18 Tilt angle dependence of $\mathrm{CC}$ temperatures with heat load to both evaporators

Figure 17 shows the loop temperature in the test where even heat loads were applied to both E1 and E2. Throughout the test, $\mathrm{CC} 1$ controlled the loop. At $60 \mathrm{~W} / 60 \mathrm{~W}$ power apply, the E1 temperature began to rise. In this point, it is considered that the loop reached capillary limit. At $75 \mathrm{~W} / 75 \mathrm{~W}$ power apply, the E1 temperature reached system upper limit. When the heat load was reduced to $5 \mathrm{~W} / 5 \mathrm{~W}$, the loop recovered from a dry-out. The CC1 and $\mathrm{CC} 2$ temperatures were also slightly higher than that at $5 \mathrm{~W} / 5 \mathrm{~W}$ prior to the vapor penetration. Overall, compared to the 7/6/05 test in Figure 9, evaporator temperature was higher and the capillary limit was 10W/10W lower.

\section{Conclusion}

Several high-power step-up tests were conducted at NASA/GSFC to characterize the capillary limit of a miniature LHP with multiple evaporators and multiple condensers. The difference in the temperature profiles with heat load to only one evaporator and with heat load to both evaporators, with and without CC temperature control, and in horizontal position and in vertical position were comprehensively demonstrated. Although the E1/CC1 and $\mathrm{E} 2 / \mathrm{CC} 2$ were symmetric configuration with the same wick material, the equilibrium temperature of the evaporator and $\mathrm{CC}$ were different. The E2/CC2 has more than twice larger thermal conductance than that of $\mathrm{E} 1 / \mathrm{CC} 1$, and as a result, E1 shows higher temperature than that of E2 in the same power application. The E1 has lower capillary limit of $100 \mathrm{~W} / 0 \mathrm{~W}$, while E2 has capillary limit of $0 \mathrm{~W} / 110 \mathrm{~W}$. When heat load was applied to both evaporators without $\mathrm{CC}$ control, the LHP reached limit at 70W/70W. When CC was actively controlled, it was difficult to ascertain the capillary limit from the temperature information. TEC power profile can be the reference of deciding its capillary limit. When the MLHP was vertically tilted so that the evaporators were above their CCs, CC temperatures were always higher than those in horizontal position, and the loop reached capillary limit at lower power than that in horizontal position due to the increase of the gravity head.

\section{References}

[1] Ku, J, “Operating Characteristics of Loop Heat Pipes," SAE Paper No. 1999-01-2007, 1999.

[2] Maidanik, Y. F., et al., "Thermoregulation of Loops with Capillary Pumping for Space Use," SAE Paper 921169, 1992.

[3] Bienert, W. B., et al., "The Proof-of-Feasibility of Multiple Evaporator Loop Heat Pipes," $10^{\text {th }}$ International Heat Pipe Conference, Stuggart, Germany, September 1997.

[4] Yun, J. S., Wolf, D. A., and E. Kroliczek, "Design and Test Results of Multi-Evaporator Loop Heat Pipes," SAE Paper No. 1999-01-2051, 1999.

[5] Goncharov, K. A., Golovin, O. A., and V. A. Kolesnikov, "Loop Heat Pipe with Several Evaporators," SAE Paper No. 2000-01-2407, 2000.

[6] Ku, J. and G. Birur, "An Experimental Study of the Operating Temperature in a Loop Heat Pipe with Two Evaporators and Two Condensers," SAE Paper No. 2001-01-2189, 2001.

[7] 7. Ku, J. and G. Birur, "Testing of a Loop Heat Pipe with Two Evaporators and Two Condensers," SAE Paper No. 2001-01-2190, 2001. 
[8] $\mathrm{Ku}, \mathrm{J}$. and G. Birur, "Active Control of the Operating Temperature in a Loop Heat Pipe with Two Evaporators and Two Condensers," SAE Paper No. 2001-01-2188, 2001.

[9] Ku, J., Ottenstein, L, Rogers, P., and K. Cheung, "Capillary Limit in a Loop Heat Pipe with a Single Evaporator," SAE paper No. 2002-01-2502, 2002.

[10] Ku, J. and G. Birur, "Capillary Limit in a Loop Heat Pipe with Dual Evaporators," SAE paper No. 2002-012503, 2002. 